\title{
Spoken Grammar: An Urgent Necessity in the EFL Context
}

\author{
Sami A. Al-wossabi ${ }^{1}$ \\ ${ }^{1}$ English Department, Faculty of Arts and Humanities, Jazan University, Jazan, Saudi Arabia \\ Correspondence: Sami A. Al-wossabi, English Department, Faculty of Arts and Humanities, Jazan University, \\ Jazan, Saudi Arabia. E-mail: sami_ed@hotmail.com
}

Received: February 2, 2014 Accepted: March 25, 2014 Online Published: May 14, 2014

doi:10.5539/elt.v7n6p19 URL: http://dx.doi.org/10.5539/elt.v7n6p19

\begin{abstract}
Recent studies in corpus linguistics have revealed apparent inconsistencies between the prescriptive grammar presented in EFL textbooks and the type of grammar used in the speech of native speakers. Such variations and learning gapsdeprive EFL learners of the actual use of English and delay their oral/aural developmental processes. The focus of this research is therefore to highlight the necessity of integrating features of spoken grammar in L2 materials. Abasic comparative analysis is carried out to describe how reported speech, mainly direct speech, is prescriptively presented in Oxford Pocket English Grammar (OPEG) in comparison to how it is descriptively presented in the Longman Grammar of Spoken and Written English (LGSWE). The analysis reveals clearly the lack of spoken grammatical features of reported speech in (OPEG). In the light of the analysis, the paper proposes the incorporation of a twofold spoken/written grammar approach targeting primarily EFL advanced learners. Pedagogical implications and considerations for the incorporation of the two-fold grammar approach are thoroughly discussed.
\end{abstract}

Keywords: comparative analysis, conversational grammar, prescriptive/descriptive grammar, OPEG/LGSWE, reported speech, spoken/written grammar

\section{Introduction}

According to Bodine (1975, p. 129), "descriptive grammar is dominant among theorists, but prescriptive grammar is taught in the schools and exercises a range of social effects". Indeed, this is the case in many EFL contexts where there has been a long tradition in teaching prescriptive grammar for learners of English particularly in EFL school settings and EFL higher education. Descriptive grammar, on the other hand, is given little attention depending greatly on the teachers' knowledge of the descriptive nature of grammar. Learners' willingness to learn grammar from a new perspective that could be relatively ambiguous to them is yet another reason why the descriptive approach of grammar is not popular in the EFL context.

It is noteworthy that prescriptive grammarians recommend the use of formal language approach in teaching grammar with an aim of not deviating from the recognized norms of the language being taught. On the other hand, contradicting with the prescriptivists' view, descriptive grammarians, call for the presentation of grammar rules as they are actually used in everyday life contexts. Honda and O'Neil $(2008$, p. 2$)$ pointed out that "Prescriptive grammarians are judgmental and attempt to change linguistic behavior of a particular sort and in a particular direction. Linguists, or mental grammarians (Descriptive), on the other hand, seek to explain the knowledge of language that guides people's everyday use of language regardless of their schooling". For Prescriptivists, forms such as, ain't, need to be avoided as they don't comply with the prescribed rules whereas for descriptivists such usage is acceptable as it reflects how people use the language on daily basis.

Many recent studies have compared particular grammatical structures in EFL/ESL traditional grammar textbooks with the corpus-based findings of language in everyday use (Barbieri \& Eckhardt, 2007; Biber \& Reppen, 2002; Gilmore, 2004). Such comparisons reveal clear evidence of the linguistic discrepancy between what is taught and what is used. For instance, many ESL/EFL grammar books give the teaching of reported speech a place in their syllabuses. However, generally speaking, the teaching units of reported speech usually involve sentence-based analysis or sentences taken directly from fictional texts, news, formal talk, etc. Such books are purely prescriptive in nature and present grammatical rules as perceived from the standard language and are principally based on written data that does not significantly reflect linguistic features of naturally occurring speech (Biber et al., 1999). Leech (2000, p. 676) stated that "Grammar has traditionally been strongly associated with the written 
medium, and this association has been reinforced by a pedagogical tradition that has placed particular emphasis on grammatical awareness in the development of writing skills".

In fact, current but a few descriptive corpus-based grammar books, the Longman Grammar of Spoken and written English (LGSWE) (Biber et al., 1999) and the Cambridge Grammar of English (CGE) (Carter \& McCarthy, 2006), have synthesized grammar rules based on how native speakers actually use them in everyday life situations. However, these books, in some way, fall into the pitfall of presenting more flexible, changeable and sometimes ambiguous rules compared to those included in prescriptive grammar books.

In view of these differences, it can be observed that the type of grammar used in EFL schools and in EFL higher education is clearly synonymous with the rules for writing correctly and that conversational grammar necessary for everyday spoken language is completely overlooked. Carter and McCarthy (2006, p. 164) argued that "Until recently, items and structures most typically found in spoken communication have not been fully described. Most grammars of English have had a bias towards the written language". However, as shown later, many English grammarians, particularly corpus linguists, are by far undertaking constant attempts to give grounding for teaching conversational grammar to EFL/ESL learners.

In the same vein with many other corpus studies, the paper strongly recommends that conversational grammar should be introduced to EFL learners. The rationale that lies behind such position is that it is, indeed, misleading to force students to practice spoken formsviathe written norms of language. Yet, it is still unclear on HOW to virtually teach it as the case for prescriptive grammar where rules are well-structured and economically explained. Some researches, in particular those of corpus based nature, tackle the issue of the necessity of including linguistic aspects of conversational grammar in L2 textbooks, claiming that EFL/ESL textbooks do not correspond to the natural occurring speech (Barbieri \& Eckhardt, 2007; Biber \& Reppen, 2002; Gilmore, 2004). The study of Barbieri and Eckhardt (2007), in particular, theorized ten principles on how corpus-based findings on reported speech can be integrated into a form-focused model of instruction. They claim that their principles, based on corpus findings, are formulated to aid learners verbalize the linguistic features of reported speech in real language use. (McCarthy, 1998, p. 150) noted that "it is hard to conceive of achieving any intermediate level of competence in a foreign language without needing to know how the speakers of that language make speech reports".

Yet, the teaching units of reported speech proposed by Barbieri and Eckhardt (2007) needs to be reconsidered as they include some structures that are linguistically complicated for EFL learners to internalize. Having a quick look at the proposed teaching activities in their study reveals the intensive compilation of different constructions that are used in different registers. Having that in mind, such activities might disturb learners with regard to their previously learnt structures. Accumulating different linguistic constructions of different structures regardless of the way they are sequenced and structured in EFL grammar textbooks could minimize or even eliminate the anticipated effects of such approach in the EFL context. Such compilation in EFL grammar textbooks could involve several presentations of linguistic structures while addressing a single grammatical rule. Pedagogical implications mentioned in corpus-based studies such as those suggested in (Barbieri \& Eckhardt, 2007), though exceptionally insightful, are written with the ESL in the mind where learners have a wider scope of L2 environment compared to EFL learners where they have limited L2 environment that is artificially manifested in the classroom.

What follows is abasic comparative analysis on the use of reported speech in OPEG to that of LGSWE. The present paper displays the lack of particular spoken linguistic features in EFL grammar textbooks focusing on $O P E G$ as an example. The analysis is carried outwith an aim to draw the attention to how spoken features of reported speech are utterly neglected in $O P E G$. Such aim is motivated by my own interest to assist EFL learners develop their oral/aural communicative competencies since such competencies are lacking in the EFL classroom due to the intensive use of prescriptive rules that are followed strictly towards more accuracy and at the expense of fluency.

\section{Reported Speech: Comparative Analysis}

The $O P E G$, following a prescriptive approach, provides several rules for teaching direct and indirectspeech, providing few examples from everyday formal talk that comply with the rules mentioned in it. OPEG, for instance, states that reported speech involves two ways of reporting what someone has said. The first is direct speech in which the speaker's exact words are repeated.

e.g. Mary: I 've bought the tickets.

She said, 'I've bought the tickets'. 
The second way is indirect speech in which we provide the exact meaning of what was said by the speaker. e.g. She said (that) she'd bought the tickets.

The $L G S W E$, following a descriptive approach based on corpora of real world contexts, focuses mainly on direct speech in its section of Grammar of Conversation and defines it as an important and persistent feature of conversation where speakers give an apparently verbatim report of what someone said. It is apparent that this definition emphasizes the fact that reportedspeech is essentially a feature of the discourse of everyday conversation. All examples presented in the $L G S W E$ are claimed to be real authentic examples in order to show how real people use real language.

Moreover, the LGSWE considerably mentions that usually when direct speech takes place in conversations, interlocutors tend to use a range of linguistic devices signaling that they are moving into direct speech mood. They often use utterance openers, such as, well, oh, okay, look, listen, etc.

e.g. Dagmar said, "oh, I sort of sense that a couple of times when I stayed at your parents' house that I didn't feel very welcome" and I said "Well, see, I told you."

However, the OPEG and many ESL/EFL grammar books do not demonstrate the use of the above mentioned discourse markers which is a crucial feature that distinguishes reported speech that occurs in naturally occurring speech from that of written texts. Such characteristic of conversation seems to be stimulating and useful for EFL learners if introduced to them as it might raise their awareness towards the possibility of using discourse markers in their oral output. Discourse markers, such as, well, ok, as, listen, hey, but, etc., could be more appealing to be used by EFL learners as they are easier to use and could aid them produce more cohesive utterances, connect their ideas and avoid breakdown in communication. In addition, the overall goal of presenting such characteristics whether in reported speech or any other linguistic forms is to help language learners sound more fluent and natural.

It is also noteworthy that the OPEG uses the verbs say/tell as the standard expected verb in all the examples illustrated in the construction of reporting speech. On the other hand, the LGSWE illustrates other alternatives for say/tell: said/told. For instance, the LGSWE demonstrates the use of the verb go which is widely used among young speakers in both American and British English.

e.g. I go "well they offered me the position man. You are not very popular down here,"

She goes"But let's go tomorrow" and she says, "Okay." (AmE)

e.g. Yeah, he went "Oh" He goes, "Who put that there? And the bit where he goes

He goes, "Urgh, cobwebs," and she goes "Piss off! ... (BrE)

e.g. And I was going, "Well, I need a lot of help." She goes, "Well just get anyone in"

The above examples show that the verb go can take various forms in reported direct speech (go, goes, went, going). However, as stated in the LGSWE, the major form is the third person singular present tense goes which reports past speech events.

The use of past progressive with reporting verbs (was/were saying) is yet another feature of reported direct speech that has not been included in many second/foreign language grammar textbooks. The LGSWE mentions that the emphasis with the past progressive is on the reported message itself and not on the act of speaking as the case is with the non-progressive aspect.

e.g. I was saying to Yvonne .. er.. I'm rapidly running out of my allowance. (BrE)

e.g. I was saying to John this morning that I was thinking of going to London for the weekend. (BrE)

Another characteristic that has been discussed inThe LGSWE, is the use of (be + like, all) as a marker in introducing reported speech Again this feature used by speakers who mark what was said by using the verb (be) followed by the particle like or they may use all preceded by a past tense form of be. It is also noted that the use of (be + like, all) in many spoken discourses could represent the speaker inner voice.

e.g. Okay cool well anyway my mom's like "I was thinking of getting them something from Hickory Farms" (laugh) I was all "Mom!” (ArE)

e.g. He goes, "Someday I might have a kid and (laugh), I'm like "No!" (ArE)

\section{Implications and Recommendations}

Based on the above comparison, it is obvious that the prescriptive and descriptive grammar approaches are not greatly incompatible to each other as the mutual purpose of both is to get the intended message across. The risk 
is that EFL learners most of the time get their messages lost whenever they try to adhere to certain specified rules of grammar. It is, therefore, more reasonable and practical to introduce EFL learners to descriptive rules for oral purposes and prescriptive rules for written purposes. This way language instructors can be less hesitated to teach both spoken and written forms of particular grammatical structures and accordingly minimize the confusion among their learners.

It is important, therefore, to rely to a great extent on collected data from real spoken genre, such as corpus-based texts, particularly, when we introduce students to a linguistic feature that exhibits its own characteristics when it occurs in a particular conversational setting. This is not to say that EFL language teachers should minimize the importance of teaching the standard rules of grammar. On the contrary, EFL learners of English are in great need to develop their writing skills whether they are specializing in English language or any other fields. Further, presenting written grammar rules to learners, particularly beginners, clears out any ambiguity or confusion while constructing their interlanguage and progressing in their developmental processes throughout the target like continuum.

However, the simultaneous presentation of both spoken and written grammar linguistic forms in L2 teaching materials might be confusing and problematic to EFL learners, unless otherwise, such integration is well-sequenced and well-structured. EFL learners may find it easier and more accessible to use, for instance, the word, "ain't" over other negated auxiliary verbs in negative sentences, such as, am not, isn't, hasn't, etc. Based on personal observations, manyEFL Arabic learners find many problems in selecting the right form of negated auxiliary verbs, tense shifting, and subject agreement in writing negative sentences needless to say how difficult would that be when it comes to speaking. Having such persistent problems, learners are more likely to abandon the use of standard negated auxiliary verb and replace it with the more flexible negation verb, "ain't". There is no harm done in doing so as far as speaking is concerned. However, the use of ain't might be applied reflexively in writing. Therefore, we need to be more cautious tailoring the presentation of spoken and written grammar forms in EFL grammar materials.

\section{Twofold Grammar Approach}

The present paper proposes the use of a balanced formal-functional approach for teaching spoken and written linguistic features to EFL learners. Such position is theoretically addressed with an aim to develop learners' communicative skills in the EFL teaching context viathe simultaneous integration of spoken and written grammar structures in L2 materials. Hence, the following are considerations for the incorporation of a twofold spoken/written grammar approach in EFL grammar textbooks. Such principles are set primarily for EFL university students, bearing in mind factors, such as, learners' level, learners' linguistic background, limited L2 environment, teaching scenario, learners' motivation, learning and teaching styles. Other future considerations and pedagogical implications, based on empirical investigations and authentic teaching practices would facilitate the teaching of conversational grammar structures in the EFL context. The following suggested considerations are influenced by the researcher's real teaching practices of spoken grammar in EFL grammar classes.

1) Spoken and written grammatical presentations necessitate specific grouping when integrated in L2 grammar textbooks. For example, spoken grammar presentation can be labeled under the name of Spoken Form while written grammar presentation can take the name of General Form as they can be used for both written and formal spoken purposes.

2) Spoken Form presentation should not be equally aligned and weighted to that of the Written Form presentation which EFL learners have been familiar with for at least six years of their previous education. It is preferred, then, that the Spoken Form presentation is placedat the end section in each lesson whether in pure L2 grammar textbook or in integrated skill textbooks.

3) The Written Form section should be introduced to students as it used be presented in their EFL grammar books, as we do not want to create a type of conflict and resistance among learners to the new learning items and /or the previous learnt items.

4) Learning and practicing spoken/written structures should be separated when FIRST introduced as long as it is clear for learners that each structure serves a different purpose.

5) Integrated learning activities of both forms can be used at the end of the lesson for the sake of recognizing the different linguistic structures being learnt.

6) Examples of conversational grammar should be simple and appealing for learners. Learners are not to be overwhelmed with ambiguous vernacular speech. The overall goal is to help EFL learners produce intelligible output. 
7) Authentic listening exercises pertaining conversational grammar structures should be an integral part of the syllabus. Listening to authentic extracts from everyday English will reinforce the learners' recognition of the features of naturally occurring speech and might lead to internalization.

8) EFL experts and language teachers should be consulted and involved in the process of tailoring spoken grammar structures in $\mathrm{L} 2$ teaching materials.

The above considerations could serve as a linguistic guide for regulating different learning items in L2 teaching materials. Such considerations and others written with the EFL in the mind, can tremendously bring about an innovative trend in the EFL learning and teaching situations. For one thing, learners will be less confused with usage appropriateness pertaining speaking or writing. Further, knowing the purpose for learning different grammatical structures, as discussed above, is crucial for subsequent and effective learning.

Based on personal teaching experience, if learners do not feel the communicative effect of learning a fixed grammatical structure on their oral production, they usually do not trouble themselves with internalizing it except for passing their language exams. Informing learners the purpose of recognizing and/or internalizing a conversational structure from real language use serves two purposes. One is receptive as EFL learners are in great need to be able to follow and comprehend utterances heard through direct contact with native speakers or in the increasingly global media of today. The other is productive as EFL learners indisputably need to verbalize intelligible utterances in the language they are learning. As (Payne, 2006, p. 142) put it out, "grammar is not an objective "representation" of a language divorced from any particular use. It is a communicative act, performed and interpreted in a context". Hence, as suggested in this paper, a twofold grammar approach for teaching written and spoken grammar can be a better practice for enhancing communicative competencies whether oral or written.

Presenting the prescriptive rules to learners and later familiarizing EFL learners with the descriptive nature of the same rules would help learners identify differences between their oral language and the language spoken by native speakers. Noticing such gaps is useful for EFL learners and as Schmidt (2001) claimed, the more learners notice, the more they will learn. Schmidt (1990, p. 129) in his Noticing Hypothesis, where he asserts the role of consciousness in learning a second language, concluded that "noticing is the necessary and sufficient condition for converting input into intake". Noticing the gap can also lead to learners' modification of their oral language as learners notice the differences between what they produce and what is produced by native speakers (Gass \& Varonis, 1994). Noticing can be more effective if learners are regularly introduced in their classes to how language is used in real life contexts. Moreover, when learners become aware of forms such as go, be like, be all, they will also have better chances to internalize them as such forms are likely to be heard in the speech of native speakers particularly on the increasingly global media of films and television in English.

Narrowing down into the purpose of this paper, integrating features of conversational grammar in L2 materials will help familiarize EFL learners with the type of conversational grammar of spoken English. Accordingly, this type of familiarity will enhance EFL learners' comprehension skills when listening to native speakers in real life contexts. EFL Arabic learners might hear words like, ain't, be like, all, in reported speech, but don't have any clue what they really mean. Such forms and many others in everyday English are important in comprehending authentic chunks of language used by native speakers. It is not surprising that listening comprehension is the most difficult of all skills for Arabic learners and as a result the listening skill is neglected if not by teachers, learners would resist listening to instructed listening tasks as it isn't similar to what they hear in talk shows, movies, etc. They do not feel that listening is an integral part of their developmental language processes. Presenting conversational grammar will not only bring the learners' attention to how language is really used but will also help them recognize linguistic forms necessary to comprehend what is being said.

\section{Conclusion}

With regard to teaching and learning grammar, several questions could be posed here; If many native speakers of many languages don't considerably comply with the use of the standard rules of grammar in their spoken discourse; why then should non-native fully comply with such rules and be precluded from the actual use of the language? Isn't it overwhelming too for EFL learners trying to incorporate such structures into their oral output? Do EFL teachers themselves adhere to the use of the prescriptive rules they are teaching? Those concerns and many others reveal to us clearly, as language instructors, the EFL unproductive educational scenario that is principally featured by the intensive mechanical teaching of prescriptive grammar rules in the EFL context. Indeed, as it is the EFL learners' right to practice using the prescriptive written side of grammar, it is our duty to help them have access to cultivate the communicative benefits of conversational grammar. 
A balanced formal-functional approach for teaching grammar is more likely to facilitate learning and using the grammar rules introduced to EFL learners. The twofold approach suggested in this paper for teaching grammar is more likely to draw its utmost benefits when used with advanced learners. Learners who have been repeatedly introduced to prescriptive written grammar earlier in their classes are more capable to conceptualize and synchronize the descriptive and/or prescriptive use of a particular grammar rule. However, to examine the instructional effectiveness of such approach future research should design and conduct a pre- and post-test of learning after instruction and exposure. Future research should investigate and document such claims and speculations with an aim to provide teachers with the best teaching practices for effective language learning.

To sum up, the paper rather suggests encouraging EFL learners to primarily recognize, not necessarily internalize, the descriptive nature of the rules of grammar. Many studies have found that EFL learners in fact prefer learning explicit prescriptive grammar rules as they have difficulties internalizing more complicated ones. Further, they found that teachers face more difficulties correcting learners' oral output than from that of written output (Al-Mekhlafi \& Nagaratnam, 2011; Burgess \& Etherington, 2002). Such internalization might be dependent greatly on EFL learners' need to communicate rather than on teachers' mere desire to accomplish their teaching missions as prescribed. Therefore, language instructors should not worry about whether descriptive rules are internalized or not. Likewise, it is the case for prescriptive rules, we cannot judge if students internalize them and are ready to use them in their oral output, and if so; how long will that last?

In conclusion, it is crucial to bear in mind that learning a language is challenging task and requires regular practice and that the ultimate goal is to communicate effectively and intelligibly. However, such practice will not make perfect unless learners are set free from the error-phobia they are experiencing in their grammar classes. The way rules are presented should make sense to learners and provide them with the means and confidence to generate language with a reasonable chance of success.

\section{Reference}

Al-Mekhlafi, A. M., \& Nagaratnam, R. P. (2011). Difficulties in teaching and learning grammar in an EFL context. International Journal of Instruction, 4(2), 69-92.

Baleghizadeh, S., \& Farshchi, S. (2010). An exploration of teachers' beliefs about the role of grammar in Iranian high schools and private language institutes. Journal of English Language Teaching and Learning, 52(212), 17-38.

Barbieri, F., \& Eckhardt, S. (2007). Applying corpus-based findings to form-focused instruction. Language Teaching Research, 11(3), 319-346. http://dx.doi.org/10.1177/1362168807077563

Biber, D., \& Reppen, R. (2002). What does frequency have to do with grammar teaching? Studies in Second Language Acquisition, 24(2), 199-208. http://dx.doi.org/10.1017/S0272263102002048

Biber, D., Johansson, S., Leech, G., Conrad, S., \& Finegan, E. (1999). Longman grammar of spoken and written English. Harlow, England: Pearson Education.

Bodine, A. (1975). Androcentrism in prescriptive grammar: Singular "they", sex-indefinite "he", and "he or she". Language in Society, 4(2), 129-146. http://dx.doi.org/10.1017/S0047404500004607

Carter, R., \& McCarthy, M. (2006). Cambridge grammar of English. Cambridge: Cambridge University Press.

Gass, S. M., \& Varonis, E. M. (1994). Input, interaction, and second language production. Studies in Second Language Acquisition, 16(3), 283-302. http://dx.doi.org/10.1017/S0272263100013097

Gilmore, A. (2004). A comparison of textbook and authentic interactions. ELT Journal, 58(4), 363-371. http://dx.doi.org/10.1093/elt/58.4.363

Honda, M., \& O’Neil, W. (2008). Thinking linguistically: A scientific approach to language. Malden, MA: Blackwell Publishing.

Leech, G. (2000). Grammars of spoken English: New outcomes of corpus-oriented research. Language Learning, 50(4), 675-724. http://dx.doi.org/10.1111/0023-8333.00143

McCarthy, M. (1998). So Mary was saying: Speech reporting in everyday conversation. In M. McCarthy (Ed.), Spoken language and applied linguistics (pp. 150-175). Cambridge: Cambridge University.

Payne, T. E. (2006). A grammar as a communicative act or what does a grammatical description really describe? Studies in Language, 30(2), 367-383.

Schmidt, R. W. (2001). Attention. In P. Robinson (Ed.), Cognition and second language instruction (pp. 3-33). New York: Cambridge University Press. 
Schmidt, R. W. (1990). The role of consciousness in second language learning. Applied Linguistics, 11(2), 129-158. http://dx.doi.org/10.1093/applin/11.2.129

Thomson, A., \& Martinet, A. (1990). Oxford pocket English grammar. Oxford University Press.

\section{Copyrights}

Copyright for this article is retained by the author(s), with first publication rights granted to the journal.

This is an open-access article distributed under the terms and conditions of the Creative Commons Attribution license (http://creativecommons.org/licenses/by/3.0/). 